\title{
CORRELATION BETWEEN AURORAL ACTIVITY AND RATE OF DEVELOPMENT OF A STORM IN ITS MAIN PHASE
}

\section{R.N. Boroyev}

Yu.G. Shafer Institute of Cosmophysical Research and Aeronomy SB RAS, Yakutsk, Russia, boroyev@ikfia.ysn.ru

We investigated the relationship between the rate of storm development in its main phase $(|\Delta D s t| / \Delta T)$ and the average value $(\Sigma A E / \triangle T)$ of $A E$ index for the main phase where $|\Delta D s t|$ is the Dst-index variation, $\Sigma A E$ is the total value of $A E$ index for the main phase of magnetic storm, $\Delta T$ is the main phase duration. We considered storms initiated by corotating interaction region (CIR) and interplanetary coronal mass ejection (ICME) (magnetic cloud and ejecta). For CIR events, the value of $\Sigma A E / \Delta T$ is shown to correlate with the rate of storm development in its main phase in contrast to the storms initiated by the ICME. As found, there is a weak correlation between $\Sigma A E / \triangle T$ and the minimum value of Dst index for CIR and ICME events.

Keywords Magnetic storm $\cdot A E$ index $\cdot$ Dst index $\cdot$ Solar wind $\cdot$ Electric field

\section{INTRODUCTION}

It is known that during periods of long-term south $B_{z}$ component of the interplanetary magnetic field (IMF) in Earth's magnetosphere along with substorm disturbances there occur magnetic storms. Effectiveness of the south IMF $B_{z}$ component in generating magnetospheric disturbances is associated with the effect of the solar wind (SW) electric field $E_{\mathrm{sw}}=V_{x} B_{z}$ on the magnetosphere [Burton et al., 1975; Gonzalez et al., 1994; Kane, 2005]. Intensity of substorm and storm disturbances is estimated from geomagnetic activity indices $A E$ and $D s t$. The high-latitude $A E$ and low-latitude $D s t$ indices representing largely the intensity of ring current and currents of the auroral zone correlate with each other because they have common drivers $\left(E_{\mathrm{sw}}\right)$. Special attention is paid to the studies of magnetospheric disturbances during the main storm phase with the most pronounced effects of SW interaction with Earth's magnetosphere. Results of statistical and morphological investigations reveal that the intensity of magnetospheric-ionospheric disturbances (magnetic storms and substorms) depends greatly on SW type [Plotnikov, Barkova, 2007; Yermolaev et al., 2010]. At present, the following SW types are distinguished: interplanetary coronal mass ejections (ISME), including magnetic clouds (MS) and ejecta, corotating interaction regions (CIR), and sheath regions. The analysis of the relationship between SW parameters for SW streams of different types and the geomagnetic activity indices $A E$ and Dst [Plotnikov, Barkova, 2007; Yermolaev et al, 2010.; Guo et al, 2011.; Yermolaev et al, 2012.; Liemohn, Katus, 2012; Nikolaeva et al, 2013.; . Cramer et al, 2013] indicates that during magnetic storms the minimum value $\left(\left|D s t_{\text {min }}\right|\right)$ increases with increasing electric field $E_{\text {sw }}$ for streams of all types. For ICME events (MC + ejecta), $\left|D s t_{\min }\right|$ attains the saturation at large values of 
$E_{\mathrm{sw}}$ [Nikolaeva et al., 2015]. Unlike $D_{\mathrm{st}}, A E$ during the main storm phase is independent of $E_{\mathrm{sw}}$ for streams of almost all types, except MS. There is a nonlinear dependence of $A E$ on $E_{\text {sw }}$ in MS events.

It should be noted that the Dst variation defines intensity not only of the ring current, but also of the current on the magnetopause, the current system of the magnetotail, and high-latitude magnetosphericionospheric currents [Feldstein et al., 2005]. Using the high-latitude $A E$ index, we can take into account the contribution of magnetospheric-ionospheric current systems to the Dst variation.

However, due to different time scales of substorm and storm disturbances, $A E$ gives only a rough idea of the role the magnetospheric-ionospheric current systems play in the development of a magnetic storm. In addition, during magnetic storms not only the intensity of auroral currents, but also their shift to lower latitudes determines the value of $A E$.

The purpose of this work is to examine the relationship between the dynamics of Dst and $A E$ variations during the main storm phase for different SW types.

\section{EXPERIMENTAL DATA}

For the analysis, magnetic storms have been selected from the catalog of large-scale phenomena of the solar wind for 1976-2000 [Yermolaev et al., 2009]. More detailed information is given on the website [ftp://ftp.iki.rssi.ru/omni/]. For the 1976-2000 period, 72 magnetic storms initiated by CIR and ICME (MC + ejecta) events have been chosen. Magnetic storms caused by a sheath region are not considered in this paper. Hourly $A E$ and $D s t$ values have been taken from the website [http://wdc.kugi.kyoto.u.ac.jp / the index.html]. The minimum negative $|D s t|$ during the magnetic storms was more than $50 \mathrm{nT}$. Moderate and strong magnetic storms after a magnetically quiet period were analyzed. For each of the event, the rate of magnetic storm development during the main storm phase $|\Delta D s t| / \Delta T$ was calculated. Duration of the main storm phase $\Delta T$ was defined as the time interval $D s t_{0}$ from the instant of a sharp decrease in $D s t$ to its minimum value $D s t_{\min }$, and $|\Delta D s t|=\mid D s t_{\min }$ - Dst $t_{0}$. To account for the displacement of the auroral oval during a magnetic storm and substorm as well as the duration of substorm disturbances (1-3 hr), the average value of $A E$ for the main phase $\Sigma$ $A E / \triangle T$ was computed, where $\Sigma A E$ is the total value of $A E$ during the main phase.

\section{RESULTS AND DISCUSSION}

Figure 1 shows the relationship between the average value of $A E(\Sigma A E / \Delta T)$ and the rate of magnetic storm development for the storms initiated by CIR (left) and ICME (right) events. Squares mark individual magnetic storms; straight lines are linear approximations. The table lists equations of linear regressions between $\Sigma A E / \triangle T$ and the rate of magnetic storm development for two SW types. For comparison, the table gives correlation coefficients and probabilities of relationship of $\Sigma A E / \triangle T$ with the rate of magnetic storm development as well as with $\left|D s t_{\min }\right| / \Delta T$ and $\left|D s t_{\min }\right|$. 

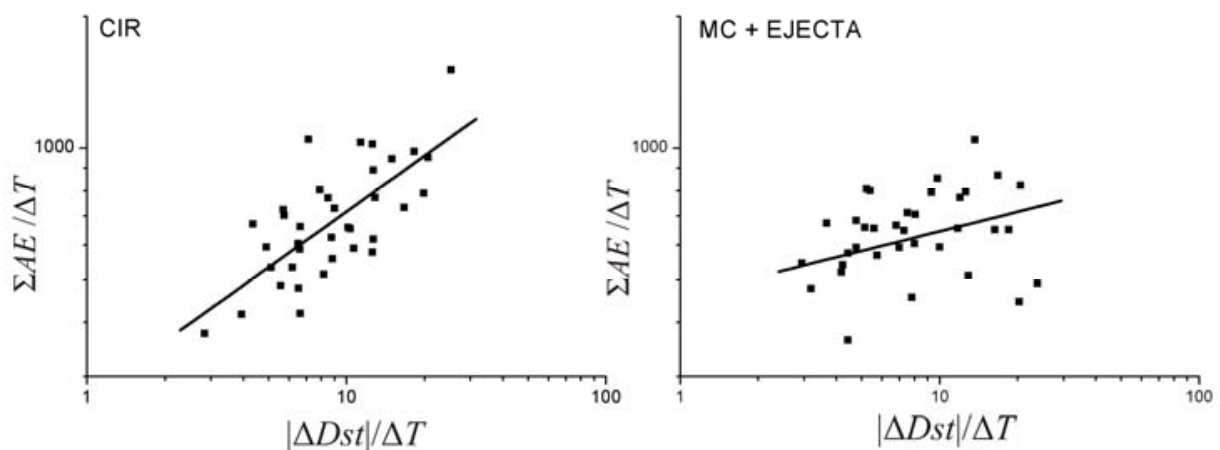

Figure 1. Relationship between $\Sigma A E / \Delta T$ and the rate of magnetic storm development $|\Delta D s t| / \Delta T$ for storms initiated by CIR and ICME (MC + ejecta) events

It can be seen that $\Sigma A E / \Delta T$ monotonically increases for different $\mathrm{SW}$ types with increasing rate of magnetic storm development. However, the analysis shows (Table) that the relationship between $\Sigma$ $A E / \Delta T$ and $|\Delta D s t| / \Delta T$ is more strongly pronounced and statistically significant for the storms initiated by CIR events $(r=0.71 ; P=99 \%)$ than for those driven by ICME $(r=0.33 ; P=97 \%)$. Thus, the average $A E$ index is clearly correlated with the rate of magnetic storm development for CIR-events, whereas for ICME events this correlation is weak. If instead of the rate of magnetic storm development $|\Delta D s t| / \Delta T$ we consider a new parameter $\left|D s t_{\min }\right| / \Delta T$, which includes $\left|D s t_{\min }\right|$ and $\Delta T$, then there is a slight increase in the correlation coefficient between $\Sigma A E / \Delta T$ and $\left|D s t_{\min }\right| / \Delta T$ in contrast to the correlation coefficient between $\Sigma A E / \Delta T$ and $|\Delta D s t| / \Delta T$ (Table).

The number of storms, correlation coefficients $r$, probabilities $P$, and approximations for the relationship of $\Sigma A E / \Delta T$ with the rate of storm development, with the parameters $\left|D s t_{\min }\right| / \Delta T$, and $\left|D s t_{\min }\right|$ for CIR and ICME initiated storms

\begin{tabular}{|l|l|c|c|c|c|c|c|c|}
\hline SW type & \multirow{2}{*}{$N$} & \multicolumn{4}{|c|}{$|\Delta D s t| / \Delta T$} & \multicolumn{2}{|c|}{$\left|D s t_{\min }\right| / \Delta T$} & \multicolumn{2}{|c|}{$\left|D s t_{\min }\right|$} \\
\cline { 3 - 9 } & & $r$ & $P$ & approximation & $r$ & $P$ & $r$ & \multicolumn{1}{c|}{$P$} \\
\hline CIR & 36 & 0.71 & 0.99 & $\ln y=0.42 \ln x+2.43$ & 0.76 & 0.99 & 0.32 & 0.95 \\
\hline ICME & 36 & 0.33 & 0.97 & $\ln y=0.14 \ln x+2.66$ & 0.35 & 0.97 & 0.26 & 0.88 \\
\hline
\end{tabular}

To evaluate the possible relationship between $\Sigma A E / \Delta T$ and $D s t$, a relationship was built between $\Sigma$ $A E / \Delta T$ and $\left|D s t_{\min }\right|$ (Figure 2). The analysis shows extremely weak correlation between them $(r<0.5)$ for different SW types (Table).
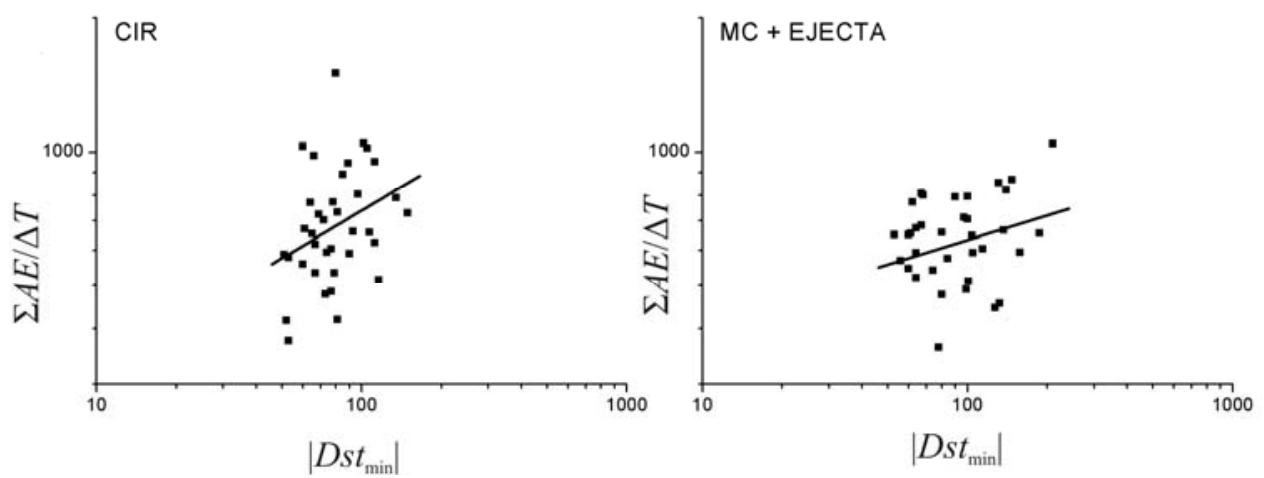

Figure 2. Relationship between $\Sigma A E / \Delta T$ and $\left|D s t_{\min }\right|$ for storms initiated by CIR and ICME (MC + ejecta) events 
It is known that the time variation of $D s t(d|D s t| / d t)$ during the main storm phase is conditioned by the SW electric field [Kane, 2010; Yermolaev et al, 2010.; Nikolaeva et al, 2014.; Yermolaev et al., 2016]. If we suppose that the $D s t$ variations are related to $|\Delta D s t| / \Delta T$, then $|\Delta D s t| / \Delta T$ is determined by the mean value of $E_{\text {sw }}$ [Yermolaev et al, 2016]. Thus, the results obtained indicate that for CIR events $\Sigma$ $A E / \Delta T$ may correlate with the average value of $E_{\mathrm{sw}}$ during the main storm phase.

\section{CONCLUSION}

In this paper, the relationship has been studied between $\Sigma A E / \Delta T$ and the rate of magnetic storm development for magnetic storms initiated by ICME (36) and CIR (36) events. The following results have been obtained.

1. During CIR events, $\Sigma A E / \Delta T$ correlates with the rate of magnetic storm development as opposed to ICME events.

2. The value of $\Sigma A E / \Delta T$ correlates weakly with $\left|D s t_{\min }\right|$ for CIR- and ICME-generated magnetic storms.

This work was supported by RFBR grant No. 15-45-05090.

\section{REFERENCES}

Burton R.K., McPherron R.L., Russell C.T. An empirical relationship between interplanetary conditions and Dst. J. Geophys. Res. 1975, vol. 80, pp. 4204-4214.

Cramer W.D., Turner N.E., Fok M.C., Buzulukova N.Y. Effects of different geomagnetic storm drivers on the ring current: CRCM results. J. Geophys. Res. 2013, vol. 118. DOI: 10.1002/jgra.50138.

Feldstein Y.I., Levitin A.E., Kozyra J.U., Tsurutani B.T., Prigancova A., Alperovich L., Gonzalez W.D., Mall U., Alexeev I.I., Gromova L.I., Dremukhina L.A. Self-consistent modeling of the large-scale distortions in the geomagnetic field during the 24-27 September 1998 major magnetic storm. J. Geophys. Res. 2005. vol. 110, no. A11. DOI: 10.1029/2004JA010584.

Guo J., Feng X., Emery B.A., Zhang J., Xiang C., Shen F., Song W. Energy transfer during intense geomagnetic storms driven by interplanetary coronal mass ejections and their sheath regions. J. Geophys. Res. 2011. vol. 116. DOI: 10.1029/2011 JA016490.

Gonzalez W.D., Joselyn J.A., Kamide Y., Kroehl H.W., Rostoker G., Tsurutani B.T., Vasyliunas V.M. What is a geomagnetic storm? J. Geophys. Res. 1994, vol. 99, pp. 5771-5792.

Kane R.P. How good is the relationship of solar and interplanetary plasma parameters with geomagnetic storms? J. Geophys. Res. 2005, vol. 110. DOI: 10.1029/2004JA010799.

Kane R.P. Scatter in the plots of Dst(min) versus $\mathrm{B}_{\mathrm{z}}(\mathrm{min})$. Planetary and Space Sci. 2010, vol. 58, pp. 792-1801.

Liemohn M.W., Katus R. Is the storm time response of the inner magnetospheric hot ions universally similar or driver dependent? J. Geophys. Res. 2005, vol. 117. DOI: 10.1029/2011JA017389.

Nikolaeva N.S., Yermolaev Yu.I., Lodkina I.G. Modeling of $D_{\mathrm{st}}$-index temporal profile in the main phase of magnetic storms generated by the solar wind of different types. Kosmicheskie issledovaniya [Cosmic Res.]. 2013, vol. 51, no. 6, pp. 443-454. (In Russian).

Nikolaeva N.S., Yermolaev Yu I., Lodkina I.G. Dependence of geomagnetic activity during magnetic storms on solar wind parameters for different types of streams: 4. Simulation for magnetic clouds. Geomagnetizm i aeronomiya [Geomagnetism and Aeronomy]. 2014, vol. 54, no. 2, pp. 163-173. (In Russian). 
Nikolaeva N.S., Yermolaev Yu.I., Lodkina I.G. Predicted dependence of the cross polar cap potential saturation on the type of solar wind stream. Adv. Space Res. 2015, vol. 56, pp. 1366-1373.

Plotnikov I.Ya., Barkova E.S. Advances in space research nonlinear dependence of Dst and AE indices on the electric field of magnetic clouds. Adv. Space Res. 2007, V. 40, pp. 1858-1862.

Yermolaev Yu.I., Nikolaeva N.S., Lodkina I.G., Yermolaev M.Yu. Catalog of large-scale solar wind phenomena during 1976-2000. Kosmicheskie issledovaniya [Cosmic Res.]. 2009, vol. 47, no. 2, pp. 99-113. (In Russian).

Yermolaev Yu.I., Nikolaeva N.S., Lodkina I.G., Yermolaev M.Yu. Specific interplanetary conditions for CIR-, sheath-, and ICME- induced geomagnetic storms obtained by double superposed epoch analysis. Ann. Geophysicae. 2010, vol. 28, pp. 2177-2186.

Yermolaev Y.I., Nikolaeva N.S., Lodkina I.G., Yermolaev M.Y. Geoeffectiveness and efficiency of CIR, sheath, and ICME in generation of magnetic storms. J. Geophys. Res. 2012, vol. 117, A00L07. DOI: 10.1029/ 2011JA017139.

Yermolaev Yu.I., Nikolaeva N.S., Lodkina I.G., Yermolaev M.Yu. Does the duration of the magnetic storm recovery phase depend on the storm development rate in its main phase? 2. New method. Geomagnetizm i aeronomiya [Geomagnetism and Aeronomy]. 2016, vol. 56, no. 3, pp. 296-301. (In Russian).

URL: ftp://ftp.iki.rssi.ru/omni/ (accessed May 12, 2016).

URL: http://wdc.kugi.kyoto.u.ac.jp/index.html (accessed May 12, 2016). 